Research Article

\title{
Area under the Curve-Based Dosing of Vancomycin in Critically Ill Patients Using 6-Hour Urine Creatinine Clearance Measurement
}

\author{
Bita Shahrami $\left(D,{ }^{1}\right.$ Farhad Najmeddin $\left(D,{ }^{1}\right.$ Saeideh Ghaffari ${ }^{(D},{ }^{2}$ Atabak Najafi $\left(D,{ }^{3}\right.$ \\ Mohammad Reza Rouini $\left(\mathbb{D},{ }^{4}\right.$ and Mojtaba Mojtahedzadeh $\mathbb{D}^{1}$ \\ ${ }^{1}$ Department of Clinical Pharmacy, Tehran University of Medical Sciences, Tehran, Iran \\ ${ }^{2}$ School of Pharmacy, Tehran University of Medical Sciences, Tehran, Iran \\ ${ }^{3}$ Department of Anesthesiology and Critical Care, Tehran University of Medical Sciences, Tehran, Iran \\ ${ }^{4}$ Department of Pharmaceutics, Tehran University of Medical Sciences, Tehran, Iran \\ Correspondence should be addressed to Mojtaba Mojtahedzadeh; mojtahed@sina.tums.ac.ir
}

Received 30 August 2020; Revised 27 November 2020; Accepted 16 December 2020; Published 24 December 2020

Academic Editor: Quincy K Tran

Copyright (c) 2020 Bita Shahrami et al. This is an open access article distributed under the Creative Commons Attribution License, which permits unrestricted use, distribution, and reproduction in any medium, provided the original work is properly cited.

Background. The area under the curve- (AUC-) guided vancomycin dosing is the best strategy for individualized therapy in critical illnesses. Since AUC can be calculated directly using drug clearance $\left(\mathrm{CL}_{\mathrm{van}}\right)$, any parameter estimating $\mathrm{CL}_{\mathrm{van}}$ will be able to achieve the goal of 24-hour AUC $\left(\mathrm{AUC}_{24 \mathrm{~h}}\right)$. The present study was aimed to determine $\mathrm{CL}_{\mathrm{van}}$ based on 6-hour urine creatinine clearance measurement in critically ill patients with normal renal function. Method. 23 adult critically ill patients with an estimated glomerular filtration rate (eGFR) $\geq 60 \mathrm{~mL} / \mathrm{min}$ who received vancomycin infusion were enrolled in this pilot study. Vancomycin pharmacokinetic parameters were determined for each patient using serum concentration data and a one-compartment model provided by MONOLIX software using stochastic approximation expectation-maximization (SAEM) algorithm. Correlation of $\mathrm{CL}_{\mathrm{van}}$ with the measured creatinine clearance in 6-hour urine collection $\left(\mathrm{CL}_{6 \mathrm{~h}}\right)$ and estimated creatinine clearance by the Cockcroft-Gault formula $\left(\mathrm{CL}_{\mathrm{CG}}\right)$ was investigated. Results. Data analysis revealed that $\mathrm{CL}_{6 \mathrm{~h}}$ had a stronger correlation with $\mathrm{CL}_{\mathrm{van}}$ rather than $\mathrm{CL}_{\mathrm{CG}}\left(r=0.823\right.$ vs. $0.594 ; p<0.001$ vs. 0.003 ). The relationship between $\mathrm{CL}_{\mathrm{van}}$ and $\mathrm{CL}_{6 \mathrm{~h}}$ was utilized to develop the following equation for estimating $\mathrm{CL}_{\mathrm{van}}$ : $\mathrm{CL}_{\mathrm{van}}(\mathrm{mL} / \mathrm{min})=-137.4+\mathrm{CL}_{6 \mathrm{~h}}(\mathrm{~mL} / \mathrm{min})+2.5 \mathrm{IBW}(\mathrm{kg})\left(R^{2}=0.826, p<0.001\right)$. Regarding the described model, the following equation can be used to calculate the empirical dose of vancomycin for achieving the therapeutic goals in critically ill patients without renal impairment: total daily dose of vancomycin $(\mathrm{mg})=\left(-137.4 \mathrm{CL}_{6-\mathrm{h}}(\mathrm{mL} /\right.$ $\mathrm{min})+2.5 \mathrm{IBW}(\mathrm{kg})) \times 0.06 \mathrm{AUC}_{24} \mathrm{~h}(\mathrm{mg} \cdot \mathrm{hr} / \mathrm{L})$. Conclusion. For AUC estimation, $\mathrm{CL}_{\mathrm{van}}$ can be obtained by collecting urine in a 6hour period with good approximation in critically ill patients with normal renal function.

\section{Introduction}

Vancomycin is still used as the standard treatment for suspected methicillin-resistant Staphylococcus aureus (MRSA) infections in intensive care units (ICUs). This feature has dramatically increased the utilization of vancomycin despite the introduction of some alternative agents $[1,2]$. Because of the narrow therapeutic range of vancomycin, therapeutic drug monitoring (TDM) is an important issue for achieving optimal levels of this antibiotic particularly among patients with critically ill conditions [3].
According to the vancomycin dosing guidelines, the area under the curve (AUC) is the best predictor for drug dosing [4]. Evidence shows the supratherapeutic threshold of vancomycin in trough levels between 15 and $20 \mathrm{mg} / \mathrm{L}$ as recommended before, and dose adjustment based on trough level alone is not an accurate estimation of 24-hour AUC $\left(\mathrm{AUC}_{24 \mathrm{~h}}\right)$ [5-7]. AUC-guided dosing is associated with a lower risk of nephrotoxicity due to reducing the irrational overuse of vancomycin $[8,9]$. Based on this, converting from the trough level to AUC has occurred for the vancomycin's therapeutic goals, and the $\mathrm{AUC}_{24 \mathrm{~h}}$ target of $400-600 \mathrm{mg} \cdot \mathrm{hr} /$ 
$\mathrm{L}$ is recommended regardless of minimum inhibitory concentration (MIC) or treated organism $[10,11]$.

Since vancomycin AUC is estimated by drug clearance, if there is a way to predict the clearance, the $\mathrm{AUC}_{24 \mathrm{~h}}$ will be easily calculated in the patients. The main route for clearance of vancomycin in the body is almost exclusively through the kidneys. Nearly most of the vancomycin is recovered unchanged in urine through glomerular filtration $[12,13]$. If the patient's kidney condition is accurately estimated, then a better decision will be made on the dose of vancomycin; furthermore, accumulation of vancomycin can cause serious side effects, including nephrotoxicity and ototoxicity [14]. The best marker for determining renal function is the glomerular filtration rate (GFR) [15]. There are several methods for measuring GFR, among which creatinine clearance (CrCL) is used based on urine collection $[16,17]$. Previous studies reported some positive aspects regarding using creatinine measurement such as easy measurement, as well as not being invasive and expensive [18]. Also, it is endogenous and does not need to be injected. Accordingly, CrCL is used as the clinical surrogate for GFR.

Currently, the guidance on the vancomycin dosing is based on the CrCL obtained from the Cockcroft-Gault (CG) equation. Since the ICU patients have unstable conditions, application of CG equation to adjust drug dosing may lead to ending up with subtherapeutic and supratherapeutic trough concentrations [19]. This equation does not consider increasing the cardiac output and renal flow rate due to hemodynamic changes and medications used in the ICU, thus underestimating CrCL or overestimating the degree of acute kidney injury (AKI) in critically ill patients [20]. As a result, assessment of renal function presents a unique challenge in critical illnesses, and it should be noted that none of the existing methods are capable of truly predicting the clearance of vancomycin $\left(\mathrm{CL}_{\mathrm{van}}\right)$. Therefore, there is a need to introduce new methods or optimize existing ones. Hence, the current study was aimed to determine $\mathrm{CL}_{\mathrm{van}}$ for AUC estimation based on 6-hour urine creatinine clearance $\left(\mathrm{CL}_{6 \mathrm{~h}}\right)$ measurement in critically ill patients with normal renal function.

\section{Materials and Methods}

2.1. Study Settings. This prospective pilot study was approved by the Institutional Ethics Committee of Tehran University of Medical Sciences (TUMS), Iran.

2.2. Patient Selection. 23 critically ill patients aged older than 18 years with a normal renal function (estimated glomerular filtration rate $(e G F R) \geq 60 \mathrm{~mL} / \mathrm{min}$ ) who received vancomycin infusion for treatment were enrolled in the study after obtaining the informed consent. None of the patients had known hypersensitivity to vancomycin, and all patients had started using this drug by attending the physicians for the treatment of presumed or documented Gram-positive infections. Patients with unstable kidney function during 48 hours before and after the first dose were excluded from the study [21]. All patients initially received a loading dose of
$25 \mathrm{mg} / \mathrm{kg}$ of vancomycin based on total body weight and with an infusion period of $\geq 30$ minutes for every $500 \mathrm{mg}$, followed by an intermittent infusion.

\subsection{Methods to Collect and Measure Vancomycin Clearance.} Serum concentrations of vancomycin were collected from a central venous (CV) line. Peak and trough levels were drawn 1-hour after the end of the infusion and 1-hour before the next dose infusion, respectively. After centrifugation, all plasma samples were analyzed by fluorescence polarization immunoassay through EMIT assays (Siemens Healthcare Diagnosis, United Kingdom, EMIT).

First-dose pharmacokinetics was performed for each individual patient using the one-compartment model. Pharmacokinetic parameters (such as $\mathrm{CL}_{\mathrm{van}}$ and $\mathrm{AUC}_{24 \mathrm{~h}}$ ) were calculated by MONOLIX software as the mean of their posterior distribution using stochastic approximation expectation-maximization (SAEM) algorithm.

Renal function was monitored for all patients using serum creatinine and urine output. CrCL was estimated using the CG formula.

$$
\mathrm{CL}_{\mathrm{CG}}=\frac{(140-\mathrm{AGE}) \times \mathrm{IBW}}{72 \times \mathrm{SCr}} \times 0.85(\text { if female }),
$$

where $\mathrm{CL}_{\mathrm{CG}}$ is the Cockcroft-Gault creatinine clearance $(\mathrm{mL} / \mathrm{min}), A G E$ is the age of the patients (years), IBW is the ideal body weight $(\mathrm{kg})$, and $\mathrm{SCr}$ is the serum creatinine $(\mathrm{mg} /$ dL).

In addition, a 6-hour urine collection was performed for measuring urinary creatinine concentration and urine volume for all patients. Then, $\mathrm{CL}_{6 \mathrm{~h}}$ can be determined as follows:

$$
\mathrm{CL}_{6 \mathrm{~h}}=\frac{V_{u} \times C_{\mathrm{uCr}}}{T \times C_{\mathrm{sCr}}},
$$

where $\mathrm{CL}_{6 \mathrm{~h}}$ is the 6-hour urine creatinine clearance $(\mathrm{mL} /$ $\min ), V_{u}$ is the urine volume $(\mathrm{mL}), \mathrm{C}_{\mathrm{uCr}}$ is the urine creatinine concentration $(\mathrm{mg} / \mathrm{dL}), T$ is the duration of urine collection (minutes), equivalent to 3600 minutes for our patients, and $\mathrm{C}_{\mathrm{sCr}}$ is the creatinine serum concentration $(\mathrm{mg} / \mathrm{dL})$.

2.4. Statistical Analysis. Correlation of $\mathrm{CL}_{\mathrm{van}}$ with the measured CrCL from the 6-hour urine collection $\left(\mathrm{CL}_{6 \mathrm{~h}}\right)$ and the estimated $\mathrm{CrCL}\left(\mathrm{CL}_{\mathrm{CG}}\right)$ was investigated by the Pearson correlation test, and the final model was achieved by linear regression analysis within a stepwise protocol. Data are presented as mean (95\% confidence interval) or median $\left(1^{\text {st }}\right.$ quarterly and $3^{\text {rd }}$ quarterly), as appropriate. All the collected data were analyzed by SPSS software version 25 . For all tests, $p$ value $<0.05$ was considered as statistically significant.

\section{Results}

The subjects of the study were the patients admitted to the general and emergency ICU wards of Sina Hospital affiliated to TUMS. A majority of the patients were male (81\%) with an average age of $45.1 \pm 19.4$ years old. The mean Acute 
TABLE 1: Pharmacokinetic parameters of vancomycin.

\begin{tabular}{lc}
\hline Measures & Mean \pm S.D. or median $\left(1^{\text {st }}\right.$ quarterly and $3^{\text {rd }}$ quarterly) \\
\hline$t_{1 / 2}(\mathrm{hr})$ & $5.7[5.2,7.0]$ \\
$V_{d} / \mathrm{kg}(\mathrm{L} / \mathrm{kg})$ & $0.75 \pm 0.23$ \\
$\mathrm{CL}_{\mathrm{van}}(\mathrm{mL} / \mathrm{min})$ & $96.2 \pm 29.9$ \\
$\mathrm{AUC}_{24 \mathrm{~h}}(\mathrm{mg} \cdot \mathrm{hr} / \mathrm{L})$ & $518[447,641]$ \\
\hline
\end{tabular}

Abbreviations: S.D.: standard deviation, $C_{p}$ : peak concentration, $C_{t}$ : trough concentration, $t_{1 / 2}$ : half-life, $V_{\mathrm{d}} / \mathrm{kg}$ : volume of distribution per kilogram, $\mathrm{CL}_{\mathrm{van}}$ : clearance of vancomycin, and $\mathrm{AUC}_{24 \mathrm{~h}}$ : 24 -hour area under the curve.

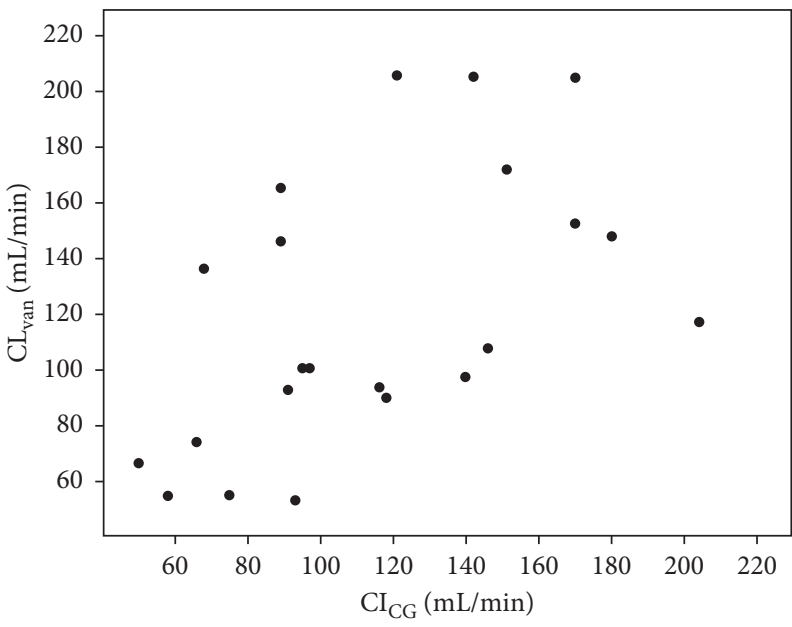

(a)

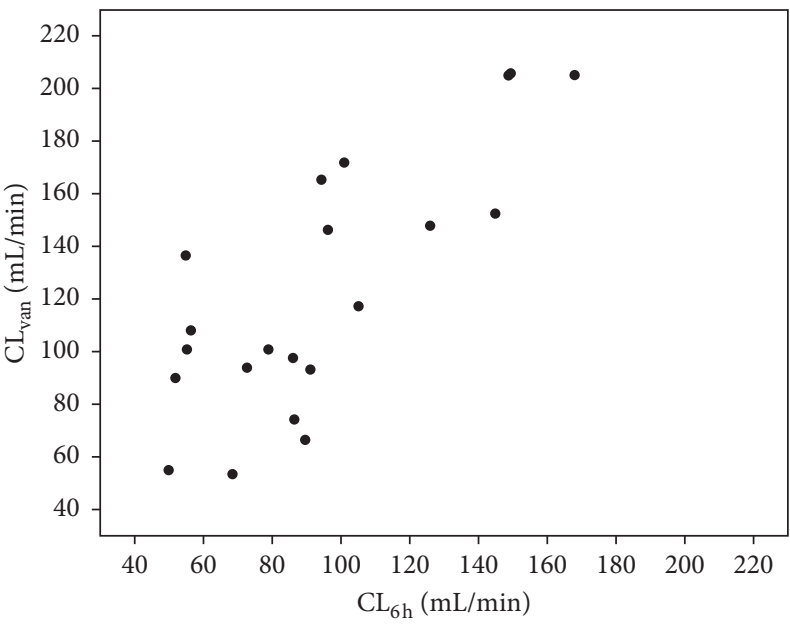

(b)

Figure 1: Comparisons between $\mathrm{CL}_{\mathrm{van}}, \mathrm{CL}_{6} \mathrm{~h}$, and $\mathrm{CL}_{\mathrm{CG}}$. (a) Correlation between $\mathrm{CL}_{\mathrm{van}}$ and $\mathrm{CL}_{\mathrm{CG}}$. (b) Correlation between $\mathrm{CL}_{\mathrm{van}}$ and $\mathrm{CL}_{6 \mathrm{~h}}$. Abbeviations: $\mathrm{CL}_{\mathrm{van}}$ : clearance of vancomycin, $\mathrm{CL}_{6 \mathrm{~h}}$ : measured creatinine clearance in 6-hour urine collection, $\mathrm{CL}_{\mathrm{CG}}$ : estimated creatinine clearance by the Cockcroft-Gault formula.

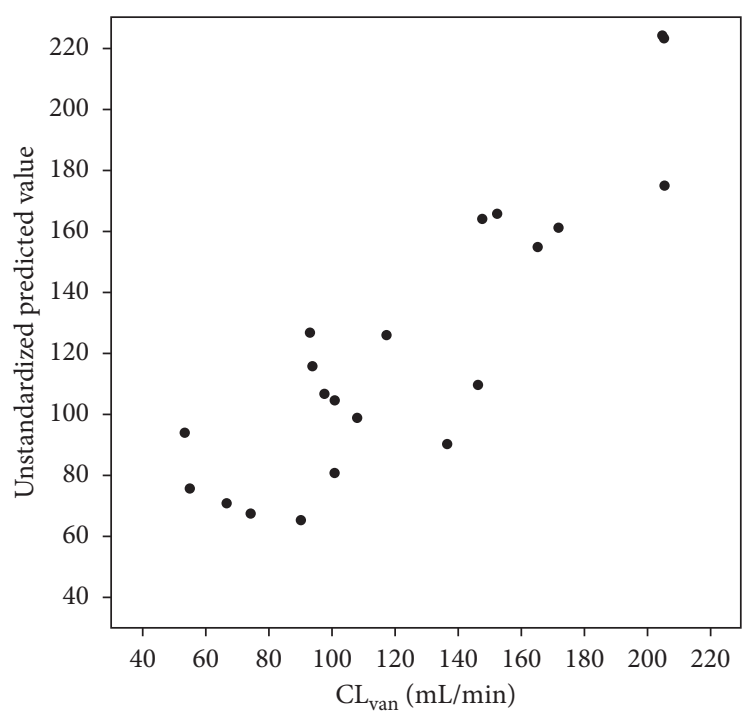

FIgURE 2: Correlation between predicted values of $\mathrm{CL}_{\mathrm{van}}$ and actual values. Abbeviations: $\mathrm{CL}_{\mathrm{van}}$ : clearance of vancomycin.

Physiology and Chronic Health Evaluation II (APACHE II) score was $12.1 \pm 1.5$. Regarding the body weight, total body weight (TBW) was $71.1 \pm 14.8 \mathrm{~kg}$, and ideal body weight
(IBW) was $68.4 \pm 9.7 \mathrm{~kg}$. The median $\left(1^{\text {st }}\right.$ quarterly and $3^{\text {rd }}$ quarterly) daily dose of vancomycin therapy was equal to $46.9[42.9,48.6] \mathrm{mg} / \mathrm{kg}$ in patients. The pharmacokinetic parameters of vancomycin studied in patients are listed in Table 1.

$\mathrm{CL}_{6 \mathrm{~h}}$ was significantly closer to $\mathrm{CL}_{\mathrm{van}}$ than $\mathrm{CL}_{\mathrm{CG}}$ $(r=0.823$ vs. $0.594 ; p<0.001$ vs. 0.003$)$. The results of comparisons between these parameters are shown in Figures 1 and 2 .

Given that the AUC depends on the clearance, different parameters were included in the regression model to find the most accurate prediction model for $\mathrm{CL}_{\mathrm{van}}$. $\mathrm{CL}_{\mathrm{CG}}, \mathrm{CL}_{6 \mathrm{~h}}$, TBW, IBW, and age were tested. $\mathrm{CL}_{6} \mathrm{~h}$ and IBW were found to be the best predictors for the model. The final equation was identified with respect to the best predictive ability to estimate $\mathrm{CL}_{\mathrm{van}}$ in critically ill patients without renal impairment as follows:

$$
\begin{aligned}
\mathrm{CL}_{\mathrm{van}}(\mathrm{mL} / \mathrm{min})= & -137.4+\mathrm{CL}_{6 \mathrm{~h}}(\mathrm{~mL} / \mathrm{min}) \\
& +2.5 \mathrm{IBW}(\mathrm{kg}) \quad(R 2=0.826, p<0.001),
\end{aligned}
$$

Regarding the described model, the practitioners can use the proposed equation to calculate the empirical dose of vancomycin to achieve the $\mathrm{AUC}_{24} \mathrm{~h}$ goal. For this purpose, the following equation can be used: 
TABLE 2: Appropriate total daily dose of vancomycin in various ranges of $\mathrm{CL}_{6 \mathrm{~h}}$ to achieve target $\mathrm{AUC}_{24 \mathrm{~h}}$ of $400 \mathrm{or} 600 \mathrm{mg} \cdot \mathrm{hr} / \mathrm{L}$ considering IBW equal to $70 \mathrm{~kg}$.

\begin{tabular}{lcr}
\hline $\mathrm{CL}_{6 \mathrm{~h}}(\mathrm{~mL} / \mathrm{min})$ & \multicolumn{2}{c}{ A total daily dose of vancomycin $(\mathrm{mg})$ to achieve target $\mathrm{AUC}_{24 \mathrm{~h}}$} \\
\hline 60 & Target $\mathrm{AUC}_{24 \mathrm{~h}}$ of $400(\mathrm{mg} \cdot \mathrm{hr} / \mathrm{L})$ & 3500 \\
80 & 2250 & 4000 \\
100 & 2750 & $4750^{*}$ \\
120 & 3250 & - \\
\hline
\end{tabular}

*Target $\mathrm{AUC}_{24 \mathrm{~h}}$ of $400 \mathrm{mg} \cdot \mathrm{hr} / \mathrm{L}$ may be considered because of the total daily dose $>4 \mathrm{~g}$. Abbreviations: $\mathrm{CL}_{6 \mathrm{~h}}$ : measured creatinine clearance in 6-hour urine collection; $\mathrm{AUC}_{24 \mathrm{~h}}$ : 24-hour area under the curve.

$$
\begin{aligned}
\text { total daily dose of vancomycin }(\mathrm{mg})= & \mathrm{CL}_{\mathrm{van}}(\mathrm{mL} / \mathrm{min}) \\
& \times \mathrm{AUC}_{24 \mathrm{~h}}(\mathrm{mg} \cdot \mathrm{hr} / \mathrm{L}) .
\end{aligned}
$$

Accordingly, $\mathrm{AUC}_{24 \mathrm{~h}}$ may be considered between 400 and $600 \mathrm{mg} \cdot \mathrm{hr} / \mathrm{L}$ based on the targeted MIC with a goal of $\mathrm{AUC}_{24 \mathrm{~h}} / \mathrm{MIC} \geq 400$; as vancomycin MIC for sensitive Staphylococcus aureus, Staphylococcus epidermidis, and Enterococcus spp. ranges between 1 and $1.5 \mathrm{mg} / \mathrm{L}$,

$$
\begin{aligned}
\text { total daily dose of vancomycin }(\mathrm{mg})= & \left(-137.4+\mathrm{CL}_{6 \mathrm{~h}}(\mathrm{~mL} / \mathrm{min})\right. \\
+ & 2.5 \mathrm{IBW}(\mathrm{kg}) \\
& \left.\times 0.06 \times \mathrm{AUC}_{24 \mathrm{~h}}(\mathrm{mg} \cdot \mathrm{hr} / \mathrm{L})\right) .
\end{aligned}
$$

Table 2 could be simply used to determine the appropriate total daily dose of vancomycin based on measured $\mathrm{CL}_{6 \mathrm{~h}}$.

\section{Discussion}

AUC-guided dosing strategy as the critical target value for individualized vancomycin dosing can be estimated using several methods including the Bayesian approach, two-point sampling, and continuous infusion [22]. Bayesian doseoptimizing software used for estimating AUC working by merging a single level of vancomycin with the populations' pharmacokinetics needs to be purchased, and many health systems, particularly in developing countries, have no access to this program [23]. Pharmacokinetic equations based on two or more vancomycin levels provide good accuracy with less bias, but it is associated with the increased laboratory workload and health-care costs [24]. Considering the limitations of current methods for AUC estimation of vancomycin, the present study was conducted to propose a new tool for achieving the therapeutic goals of vancomycin therapy and could be considered as an alternative method for empirical dosing when the lab data are available.

In case of critical illnesses, equations used for estimating renal function including CG formula are not able to provide correct judgment because this formula is based on the kidney status of the healthy men, and factors such as muscle mass, excess fat, or fluid in obese subjects and secretion of creatinine from renal tubules are not considered in this formula $[6,25]$. Moreover, the CG equation is insensitive and is not capable of showing abrupt and acute changes in kidney condition since changes in the serum creatinine status do not occur quickly [26, 27]. Besides, this formula is no longer recommended for estimating vancomycin clearance and consequently for maintenance dosing's $[28,29]$. According to the results of a current systematic review [30], using urinary CrCL is the best diagnostic method for estimating drug dosing in augmented renal clearance (ARC). 24-hour urine collection is often difficult, and some limitations are reducing the accuracy of collecting urine within 24 hours [31, 32]. In case of the critical condition of the ICU, requiring quick decision-making urine collection can be implemented by decreasing the time of urine collection. Several studies have been conducted to compare the results of 24-hour urine collection with those collected in less duration, and it has been concluded that 24-hour urine collection can be replaced with urine collection in less time [32-34]. Nevertheless, few of them have compared the urine CrCL with drug clearance such as vancomycin, which is almost completely removed from the kidneys. Rodvold et al. included a larger sample of 37 patients into three groups based on measured 24-hour CrCL including patients with renal impairment. The resulting equation $\left(\mathrm{CL}_{\mathrm{van}}(\mathrm{mL} / \mathrm{min} /\right.$ $\left.\left.1.73 \mathrm{~m}^{2}\right)=15.7+0.79 \mathrm{CL}_{24 \mathrm{~h}}\left(\mathrm{~mL} / \mathrm{min} / 1.73 \mathrm{~m}^{2}\right)\right)$ produces similar results to the equation derived in this study [35]. Zokufa et al. have suggested that renal biomarkers measurement (e.g., cystatin C) may be used to estimate $\mathrm{CrCL}$ and to determine the vancomycin dosing in ICU patients [36].

To our knowledge, this is the first research using 6-hour urine collection in ICU and comparing it with $\mathrm{CL}_{\text {van }}$ and $\mathrm{CG}$ equation in patients with normal renal function and including ARC. The 6-hour urine collection was selected as urine collection in our ICU is performed every 3 hours under the supervision of nurses, and the 6-hour duration only involves the participation of one nurse in this process and may reduce the errors. In this study, a strong relationship was found between $\mathrm{CL}_{\mathrm{van}}$ and $\mathrm{CL}_{6 \mathrm{~h}}$. Therefore, a new modeling trend was determined for vancomycin dosing based on urine collection as an alternative method for empirical initiation while waiting for serum level measurements.

4.1. Study Limitations. Since this research was a singlecenter pilot study, the described model should be confirmed by further studies with large multicenter data to evaluate vancomycin $\mathrm{AUC}_{24 \mathrm{~h}}$ based on 6-hour urine $\mathrm{CrCL}$ 
measurement in ICU patients. The described model only fits the patients with an $e G F R \geq 60$, and this could be considered as another important limitation of this study. On the other hand, as shown in the plots, this model may fit accurately in patients with ARC. Since the sample size of this study was small, we could not perform multiple adjustments for any other independent variables. However, we included one variable for every ten patients $(1: 10)$ into the multiple linear regression model to have enough power.

\section{Conclusions}

Considering the cost and labor intensity related to applying the TDM process, the results of the present study revealed that, for AUC estimation, $\mathrm{CL}_{\mathrm{van}}$ can be obtained by collecting urine in a 6-hour period with good approximation in critically ill patients with normal renal function.

\section{Data Availability}

The figure and table data used to support the findings of this study are included within the article.

\section{Conflicts of Interest}

The authors declare that they have no conflicts of interest.

\section{Acknowledgments}

The authors would like to thank the support of Sina Hospital in Tehran, Iran.

\section{References}

[1] H. Hanberger, S. Walther, M. Leone et al., "Increased mortality associated with meticillin-resistant Staphylococcus aureus (MRSA) infection in the intensive care unit: results from the EPIC II study," International Journal of Antimicrobial Agents, vol. 38, no. 4, pp. 331-335, 2011.

[2] K. A. Barie, J. P. Cannon, and S. A. Grim, "Alternative agents to vancomycin for the treatment of methicillin-resistant Staphylococcus aureus infections," American Journal of Therapeutics, vol. 20, no. 2, pp. 200-212, 2013.

[3] T. W. Felton, W. W. Hope, and J. A. Roberts, "How severe is antibiotic pharmacokinetic variability in critically ill patients and what can be done about it?" Diagnostic Microbiology and Infectious Disease, vol. 79, no. 4, pp. 441-447, 2014.

[4] M. J. Rybak, J. Le, T. P. Lodise et al., "Therapeutic monitoring of vancomycin for serious methicillin-resistant Staphylococcus aureus infections: a revised consensus guideline and review by the American society of health-system pharmacists, the infectious diseases society of America, the pediatric infectious diseases society, and the society of infectious diseases pharmacists," American Journal of Health-System Pharmacy.vol. 77, no. 11, pp. 835-864, 2020.

[5] B. Shahrami, F. Najmeddin, S. Mousavi, A. Ahmadi, and M. Mojtahedzadeh, "Therapeutic drug monitoring of vancomycin following critical care illnesses: peak concentration determination maybe critical," Journal of Pharmaceutical Care, vol. 2, no. 3, pp. 137-139, 2014.

[6] M. Haeseker, S. Croes, C. Neef, C. Bruggeman, L. Stolk, and A. Verbon, "Evaluation of vancomycin prediction methods based on estimated creatinine clearance or trough levels," Therapeutic Drug Monitoring, vol. 38, no. 1, pp. 120-126, 2016.

[7] R. B. Turner, K. Kojiro, R. Won, E. Chang, D. Chan, and F. Elbarbry, "Prospective evaluation of vancomycin pharmacokinetics in a heterogeneous critically ill population," Diagnostic Microbiology and Infectious Disease, vol. 92, no. 4, pp. 346-351, 2018.

[8] N. A. Finch, E. J. Zasowski, K. P. Murray et al., "A quasi-experiment to study the impact of vancomycin area under the concentration-time curve-guided dosing on vancomycin-associated nephrotoxicity," Antimicrobial Agents and Chemotherapy, vol. 61, no. 12, pp. e01293-e01217, 2017.

[9] B. Shahrami, F. Najmeddin, S. Mousavi et al., "Achievement of vancomycin therapeutic goals in critically ill patients: early individualization may be beneficial," Critical care research and practice, vol. 2016, Article ID 1245815, 7 pages, 2016.

[10] K. Matsumoto, Y. Takesue, N. Ohmagari et al., "Practice guidelines for therapeutic drug monitoring of vancomycin: a consensus review of the japanese society of chemotherapy and the Japanese society of therapeutic drug monitoring," Journal of Infection and Chemotherapy, vol. 19, no. 3, pp. 365-380, 2013.

[11] E. L. Mochizuki, K. C. Claeys, R. P. Mynatt et al., "Making the change to area under the curve-based vancomycin dosing," American Journal of Health-System Pharmacy, vol. 75, no. 24, pp. 1986-1995, 2018.

[12] L. Hopkins, L. K. Krcmova, P. Solich, and M. Kaska, "Simple and rapid quantification of vancomycin in serum, urine and peritoneal/pleural effusion via UHPLC-MS/MS applicable to personalized antibiotic dosing research," Journal of Pharmaceutical and Biomedical Analysis, vol. 142, pp. 59-65, 2017.

[13] S. Spadaro, A. Berselli, A. Fogagnolo et al., "Evaluation of a protocol for vancomycin administration in critically patients with and without kidney dysfunction," BMC Anesthesiology, vol. 15, no. 1, p. 95, 2015.

[14] F. Bruniera, F. Ferreira, L. Saviolli et al., "The use of vancomycin with its therapeutic and adverse effects: a review," European Review for Medical and Pharmacological Sciences, vol. 19, no. 4, pp. 694-700, 2015.

[15] W. L. Eppenga, C. Kramers, H. J. Derijks, M. Wensing, J. F. M. Wetzels, and P. A. G. M. De Smet, "Drug therapy management in patients with renal impairment: how to use creatinine-based formulas in clinical practice," European Journal of Clinical Pharmacology, vol. 72, no. 12, pp. 14331439, 2016.

[16] E. Cartet-Farnier, L. Goutelle-Audibert, P. Maire, B. De la Gastine, and S. Goutelle, "Implications of using the MDRD or CKD-EPI equation instead of the cockcroft-Gault equation for estimating renal function and drug dosage adjustment in elderly patients," Fundamental \& Clinical Pharmacology, vol. 31, no. 1, pp. 110-119, 2017.

[17] J. P. Baptista, "Augmented renal clearance," in Antibiotic Pharmacokinetic/Pharmacodynamic Considerations in the Critically Ill, A. A. Udy, J. A. Roberts, and J. Lipman, Eds., pp. 125-150, Springer Singapore, Singapore, Singapore, 2018.

[18] R. Jelliffe, "Chapter 5 - evaluation of renal function," in Individualized Drug Therapy for Patients, R. W. Jelliffe and M. Neely, Eds., pp. 47-56, Academic Press, Boston, MA, USA, 2017.

[19] J. Truong, S. R. Smith, J. J. Veillette, and S. C. Forland, "Individualized pharmacokinetic dosing of vancomycin reduces time to therapeutic trough concentrations in critically ill patients," The Journal of Clinical Pharmacology, vol. 58, no. 9, pp. 1123-1130, 2018. 
[20] F.-L. Lin Wu, S.-S. Liu, T.-Y. Yang et al., "A larger dose of vancomycin is required in adult neurosurgical intensive care unit patients due to augmented clearance," Therapeutic Drug Monitoring, vol. 37, no. 5, pp. 609-618, 2015.

[21] R. L. Win, J. A. Kellum, S. V. Shah et al., “Acute kidney injury network: report of an initiative to improve outcomes in acute kidney injury," Critical Care, vol. 11, no. 2, R31 pages, 2007.

[22] N. E. Molitoris, "Using AUC/MIC to guide vancomycin dosing: ready for prime time?" Clinical Microbiology and Infection, vol. 26, no. 4, pp. 406-408, 2020.

[23] R. B. Turner, K. Kojiro, E. A. Shephard et al., "Review and validation of bayesian dose-optimizing software and equations for calculation of the vancomycin area under the curve in critically ill patients," Pharmacotherapy: The Journal of Human Pharmacology and Drug Therapy, vol. 38, no. 12, pp. 1174-1183, 2018.

[24] L. Won, T. Wong, S. Huang et al., "Conversion from vancomycin trough concentration-guided dosing to area under the curve-guided dosing using two sample measurements in adults: implementation at an academic medical center," Pharmacotherapy: The Journal of Human Pharmacology and Drug Therapy, vol. 39, no. 4, pp. 433-442, 2019.

[25] E. Den Bakker, R. Gemke, J. A. E. van Wijk, I. Hubeek, B. Stoffel-Wagner, and A. Bökenkamp, "Combining GFR estimates from cystatin $\mathrm{C}$ and creatinine-what is the optimal mix?" Pediatric Nephrology, vol. 33, no. 9, pp. 1553-1563, 2018.

[26] A. A. Udy, J. A. Roberts, and J. Lipman, "Implications of augmented renal clearance in critically ill patients," Nature Reviews Nephrology, vol. 7, no. 9, pp. 539-543, 2011.

[27] B. Shahrami, F. Najmeddin, M. R Rouini et al., "Evaluation of amikacin pharmacokinetics in critically ill patients with intraabdominal sepsis," Advanced Pharmaceutical Bulletin, vol. 10, no. 1, pp. 114-118, 2020.

[28] M. MojtahedzadehNajafi, J. Hartinger, I. Š Netíková, and O. Slanar, "Creatinine clearance estimations for vancomycin maintenance dose adjustments," American Journal of Therapeutics, vol. 25, no. 5, pp. e602-e604, 2018.

[29] M. Šíma, J. Hartinger, T. Grus, and O. Slanař, "Initial dosing of intermittent vancomycin in adults: estimation of dosing interval in relation to dose and renal function," European Journal of Hospital Pharmacy, vol. 54, no. 6, pp. 702-708, 2019.

[30] I. Bilbao-Meseguer, A. Rodríguez-Gascón, H. Barrasa, A. Isla, and M. Á. Solinís, "Augmented renal clearance in critically ill patients: a systematic review," Clinical Pharmacokinetics, vol. 57, no. 9, pp. 1107-1121, 2018.

[31] T. Young, M. Daniel, S. Baumhover, D. Eidson, and J. Green, "Methodological study of vancomycin dosing in elderly patients using actual serum creatinine versus rounded serum creatinine," Drugs in R\&D, vol. 17, no. 3, pp. 435-440, 2017.

[32] M. E. Herrera-Gutiérrez, G. Seller-Pérez, E. Banderas-Bravo, J. Muñoz-Bono, M. Lebrón-Gallardo, and J. F. FernandezOrtega, "Replacement of $24 \mathrm{~h}$ creatinine clearance by $2 \mathrm{~h}$ creatinine clearance in intensive care unit patients: a singlecenter study," Intensive Care Medicine, vol. 33, no. 11, pp. 1900-1906, 2007.

[33] J. P. Baptista, J. A. Roberts, E. Sousa, R. Freitas, N. Deveza, and J. Pimentel, "Decreasing the time to achieve therapeutic vancomycin concentrations in critically ill patients: developing and testing of a dosing nomogram," Critical Care, vol. 18, no. 6, p. 654, 2014.
[34] S. Pong, W. Seto, M. Abdolell et al., "12-hour versus 24-hour creatinine clearance in critically ill pediatric patients," Pediatric Research, vol. 58, no. 1, pp. 83-88, 2005.

[35] K. A. Trope, R. A. Blum, J. H. Fischer et al., "Vancomycin pharmacokinetics in patients with various degrees of renal function," Antimicrobial Agents and Chemotherapy, vol. 32, no. 6, pp. 848-852, 1988.

[36] M. G. Zokufa, J. W. Hilpert, C. Gnewuch, F. Kees, and S. Voegeler, "Clearance of vancomycin during continuous infusion in intensive care unit patients: correlation with measured and estimated creatinine clearance and serum cystatin C," International Journal of Antimicrobial Agents, vol. 36 , no. 6 , pp. 545-548, 2010. 